\title{
Copyright: Regulation Out of Line with Our Digital Reality?
}

Abigail J. McDermott

\begin{abstract}
This paper provides a brief overview of the current state of copyright law in the United States, focusing on the negative impacts of these policies on libraries and patrons. The article discusses four challenges current copyright law presents to libraries and the public in general, highlighting three concrete ways intellectual property law interferes with digital library services and systems. Finally, the author suggests that a greater emphasis on copyright literacy and a commitment among the library community to advocate for fairer policies is vital to correcting the imbalance between the interests of the public and those of copyright holders.
\end{abstract}

\section{INTRODUCTION}

In July 2010, the library community applauded when Librarian of Congress James H. Billington announced new exemptions to the Digital Millennium Copyright Act (DMCA). Those with visual disabilities and the librarians who serve them can now circumvent digital rights management (DRM) software on e-books to activate a read-aloud function. ${ }^{1}$ In addition, higher education faculty in departments other than film and media studies can now break through DRM software to include high-resolution film clips in class materials and lectures. However, their students cannot, since only those who are pursuing a degree in film can legally do the same. ${ }^{2}$ That means that English students who want to legally include high-resolution clips from the critically acclaimed film Sense and Sensibility in their final projects on Jane Austin's novel will have to wait another three years, when the Librarian of Congress will again review the DMCA.

The fact that these new exemptions to the DMCA were a cause for celebration is one indicator of the imbalanced state of the copyright regulations that control creative intellectual property in this country. As the consumer-advocacy group Public Knowledge asserted, "We continue to be disappointed that the Copyright Office under the Digital Millennium Copyright Act can grant extremely limited exemptions and only every three years. This state of affairs is an indication that the law needs to be changed." 3

This paper provides a brief overview of the current state of U.S. copyright law, especially developments during the past fifteen years, with a focus on the negative impact these policies have had and will continue to have on libraries, librarians, and the patrons they serve. This paper does not provide a comprehensive and impartial primer on copyright law, a complex

Abigail J. McDermott (ajmcderm@umd.edu) is Graduate Research Associate, The Information Policy and Access Center (iPAC), and Masters Candidate in Library Science, University of Maryland, College Park. 
and convoluted topic, instead identifying concerns about the effects an out-of-balance intellectual property system is having on the library profession, library services, and creative expression in our digital age. As with any area of public policy, the battles over intellectual property issues create an every fluctuating copyright environment, and therefore, this article is written to be current with policy developments as of October 2011. Finally, this paper recommends that librarians seek to better educate themselves about copyright law, and some innovative responses to an overly restrictive system, so that we can effectively advocate on our own behalf, and better serve our patrons.

\section{THE STATE OF U.S. COPYRIGHT LAW}

Copyright law is a response to what is known as the "progress clause" of the Constitution, which charges Congress with the responsibility "to promote the Progress of Science and the useful Arts ... to this end, copyright assures authors the right to their original expression, but encourages others to build freely upon the ideas and information conveyed by a work." 4 Fair use, a statutory exception to U.S. copyright law, is a complex subject, but a brief examination of the principle gets to the heart of copyright law itself. When determining fair use, courts consider

1. the purpose and character of the use;

2. the nature of the copyrighted work;

3. the amount and substantiality of the portion used in relation to the copyrighted work as a whole; and

4. the effect of the use upon the potential market for the copyrighted work. ${ }^{5}$

While fair use is an "affirmative defense" to copyright infringement, 6 invoking fair use is not the same as admitting to copyright infringement. Teaching, scholarship, and research, as well as instances in which the use is not-for-profit and noncommercial, are all legitimate examples of fair use, even if fair use is determined on a case-by-case basis. ${ }^{7}$

Despite the byzantine nature of copyright law, there are four key issues that present the greatest challenges and obstacles to librarians and people in general: the effect of the DMCA on the principle of fair use; the dramatic extension of copyright terms codified by the Sonny Bono Copyright Term Extension Act; the disappearance of the registration requirement for copyright holders; and the problem of orphan works.

\section{The Digital Millennium Copyright Act (DMCA)}

The DMCA has been controversial since its passage in 1998. Title I of the DMCA implements two 1996 World Intellectual Property Organization (WIPO) treaties that obligate member states to enforce laws that make tampering with DRM software illegal. The DMCA added chapter 12 to the U.S. Copyright Act (17 U.S.C. §§ 1201-1205), and it criminalized the trafficking of "technologies designed to circumvent access control devices protecting copyrighted material from unauthorized 
copying or use." 8 While film studios, e-book publishers, and record producers have the right to protect their intellectual property from illegal pirating, the DMCA struck a serious blow to the principle of fair use, placing librarians and others who could likely claim fair use when copying a DVD or PDF file in a Catch-22 scenario. While the act of copying the file may be legal according to fair use, breaking through any DRM technology that prevents that copying is now illegal. ${ }^{9}$

\section{The Sonny Bono Copyright Term Extension Act}

While the Copyright Act of 1790 only provided authors and publishers with twenty-eight years of copyright protection, the Sonny Bono Copyright Term Extension Act of 1998 increased the copyright terms of all copyrighted works that were eligible for renewal in 1998 to ninety-five years after the year of the creator's death. In addition, all works copyrighted on or after January 1 , 1978, now receive copyright protection for the life of the creator plus seventy years (or ninety-five years from the date of publication for works produced by multiple creators). ${ }^{10}$ Jack Valenti, former president of the Motion Picture Association of American, was not successful in pushing copyright law past the bounds of the Constitution, which mandates that copyright be limited, although he did try to circumvent this Constitutional requirement by suggesting that copyright terms last forever less one day. ${ }^{11}$

\section{The Era of Automatic Copyright Registration}

Perhaps the most problematic facet of modern U.S. copyright law appears at first glance to be the most innocuous. The Copyright Act of 1976 did away with the registration requirement established by the Copyright Act of 1790.12 That means that any creative work "fixed in any tangible medium of expression" is automatically copyrighted at the moment of its creation. ${ }^{13}$ That includes family vacation photos stored on a computer hard drive; they are copyrighted and your permission is required to use them. The previous requirement of registration meant authors and creators had to actively register their works, so anything that was not registered entered the public domain, replenishing that important cultural realm. ${ }^{14}$ Now that copyright attaches at the moment an idea is expressed through a cocktail napkin doodle or an outline, virtually nothing new enters the public domain until its copyright term expires-at least seventy years later. In fact, nothing new will enter the public domain through copyright expiration until 2019. Until then, the public domain is essentially frozen in the year $1922 .{ }^{15}$

\section{The Problem of Orphan Works}

In addition, the incredibly long copyright terms that apply to all books, photographs, and sound recordings have created the problem of orphan works. Orphan works are those works that are under copyright protection, but whose owners are difficult or impossible to locate, often due to death. ${ }^{16}$ These publications are problematic for researchers, librarians, and the public in general: Orphan works are perceived to be inaccessible because of the risk of infringement liability that a user might incur if and when a copyright owner subsequently appears. Consequently, many works that are, 
in fact, abandoned by owners are withheld from public view and circulation because of uncertainty about the owner and the risk of liability. ${ }^{17}$

If copyright expired with the death of the author, or if there were a clause that would allow these works to pass into the public domain if the copyright holder's heirs did not actively renew copyright for another term, then these materials would be far less likely to fall into legal limbo. Currently, many are protected despite the fact that acquiring permission to use them is all but impossible. A study of orphan works in the collections of United Kingdom public sector institutions found that these works are likely to have little commercial value, but high "academic and cultural significance," and when contacted, these difficult-to-trace rights holders often grant permission for reproduction without asking for compensation. ${ }^{18}$ Put another way, orphan works are essentially "locking up culture and other public sector content and preventing organizations from serving the public interest."19

The row that arose in September 2011 between the HathiTrust institutions and the Authors Guild over the University of Michigan's orphan works digitization project, with J. R. Salamanca's longout-of-print 1958 novel The Lost Country serving as the pivot point in the dispute, is an example of the orphan works problem. The fact that University of Michigan Associate University Librarian John Price Wilkin was forced to assure the public that "no copyrighted books were made accessible to any students" illustrates the absurdity in arguing over whether it's right to digitize books that are no longer even accessible in their printed form..$^{20}$

\section{LIBRARIES, DIGITIZATION, AND COPYRIGHT LAW: THE QUIET CRISIS}

While one can debate if U.S. copyright law is still oriented toward the public good, the more relevant question in this context is the effect copyright law has on the library profession. DRM technology can get in the way of serving library patrons with visual disabilities and every library needs to place a copyright disclaimer on the photocopiers, but how much more of a stumbling block is intellectual property law to librarians in general, and the advance of library systems and technology in particular? The answer is undeniably that current U.S. copyright legislation places obstacles in the way of librarians working in all types of libraries. While there are many ways that copyright law affects library services and collections in this digital area, three challenges are particularly pressing: the problem of ownership and licensing of digital content or collections; the librarian as de facto copyright expert; and copyright law as it relates to library digitization programs generally, and the Google Book settlement in particular.

\section{Digital Collections: Licenses Replace Ownership}

In the past, people bought a book, and they owned that copy. There was little they could accidentally or unknowingly do to infringe on the copyright holder's rights. Likewise, when physical collections were their only concern, librarians could rely on Sections 108 and 109 of the copyright law to protect them from liability when they copied a book or other work and when they loaned materials in their collections to patrons. ${ }^{21}$ Today, we live partly in the physical world and 
partly in the digital world, reaching out and connecting to each other across fiber optic lines in the same way we once did around the water cooler. Likewise, the digital means of production are widely distributed. In a multimedia world, where sharing an informative or entertaining video clip is as easy as embedding a link onto someone's Facebook wall, the temptation to infringe on rights by distributing, reproducing, or displaying a creative work is all too common, and all too easy. ${ }^{22}$

Many librarians believe that disclaimers on public-access computer terminals will protect them from lawsuit, but they do not often consider placing such disclaimers on their CD or DVD collections. Yet a copyright holder would not have to prove the library is aware of piracy to accuse the library of vicarious infringement of copyright. The copyright holder may even be able to argue that the library sees some financial gain from this piracy if the existence of the material that is being pirated serves as the primary reason a patron visits the library. ${ }^{23}$ Even the physical CD collection in the public library can place the institution in danger of copyright infringement; yet the copyright challenges raised by cutting-edge digital resources, like e-books, are undoubtedly more complicated.

E-books are replacing traditional books in many contexts. Like most digital works today, e-books are licensed, not purchased outright. The problem licensing presents to libraries is that licensed works are not sold, they are granted through contracts, and contracts can change suddenly and negate fair-use provisions of U.S. copyright law. ${ }^{24}$ While libraries are now adept at negotiating contracts with subscription database providers, e-books are in many ways even more difficult to manage, with many vendors requiring that patrons delete or destroy the licensed content on their personal e-readers at the end of the lending period..$^{25}$ The entire library community was rocked by HarperCollins's February 2011 decision to limit licenses on e-books offered through library ebook vendors like OverDrive to twenty-six circulations, with many librarians questioning the publisher's assertion that this seemingly arbitrary limitation is related to the average lifespan of a single print copy. ${ }^{26}$

License holders have an easy time arguing that any use of their content without paying fees is a violation of their copyright. That is not the case when a fair use argument is justified, and while many in the library community may acquiesce to these arguments, "in recent cases, courts have found the use of a work to be fair despite the existence of a licensing market."27 When license agreements are paired with DRM technology, libraries may find themselves managing thousands of micropayments to allow their users to view, copy, move, print, or embed, for example, the PDF of a scholarly journal article. ${ }^{28}$ In the current climate of reduced staff and shrinking budgets, managing these complex licensing agreements has the potential to cripple many libraries.

\section{The Librarian as Accidental Copyright Czar}

During a Special Libraries Association (SLA) Q\&A session on copyright law in the digital age, the questions submitted to the panel came from librarians working in hospitals, public libraries, academic libraries, and even law libraries. Librarians are being thrust into the position of de facto copyright expert. One of the speakers mentioned that she must constantly remind the lawyers at 
the firm she works for that they should not copy and paste the full text of news or law review journal articles into their e-mails, and instead, they should send a link. The basis of her argument is the third factor of fair use mentioned earlier: the amount or substantiality of the portion of the copyrighted work being used. ${ }^{29}$ Since fair use is not a "bright line" principle, the more factors you have on your side the better when you are using a copyrighted work without the owners express permission. ${ }^{30}$

Librarians working in any institution must seek express permission from copyright holders for any video they wish to post, or embed, on library-managed websites. E-reserves and streaming video, mainstays of many educators and librarians seeking to capture the attention of this digital generation, have become bright red targets for litigious copyright holders who want to shrink the territory claimed under the fair-use banner even further. Many in the library community are aware of the Georgia State University e-reserves lawsuit, Cambridge University Press et al. v. Patton, in which a group of academic publishers have accused the school of turning its e-reserves system into a vehicle for intentional piracy. ${ }^{31}$ University librarians are implicated for not providing sufficient oversight. It has come to light that the Association of American Publishers (AAP) approached other schools, including Cornell, Hofstra, Syracuse, and Marquette, before filing a suit against Georgia State. Generally, the letters come from AAPs outside counsel and are accompanied by "the draft of a federal court legal complaint that alleges copyright infringement." 32 The AAP believes that e-reserves are by nature an infringement of copyright law, so they demand these universities work with their association to draft guidelines for electronic content that support AAPs "cost-per-click theory of contemporary copyright: no pay equals no click."33 It seems that Georgia State was not willing to quietly concede to AAP's view on the matter, and they are now facing the association in court. ${ }^{34} \mathrm{~A}$ decision in this case was pending at the time this article went to press.

The case brought by the Association for Information and Media Equipment (AIME) against UCLA is similar, except it focuses on the posting of videos so they can be streamed by students on password-protected university websites that do not allow the copying or retention of the videos. ${ }^{35}$ UCLA argued that the video streaming services for students are protected by the Technology Education and Copyright Harmonization (TEACH) Act of 2002, which is the same act that allows all libraries to offer patrons online access to electronic subscription databases off-site through a user-authentication system. ${ }^{36}$ In addition, UCLA argues that it is simply allowing its students to "time shift" these videos, a practice deemed not to infringe on copyright law by the Supreme Court in its landmark Sony Corp. v. Universal City Studios, Inc. decision of 1984. ${ }^{37}$ The American Library Association (ALA), Association of Research Libraries (ARL), and the Association of College and Research Libraries (ACRL) jointly published an opinion supporting UCLA in this case. Many in the wider library community sympathized with UCLA's library administrators, who cite budget cuts that reduced hours at the school's media laboratory as one reason they must now offer students a video-streaming option. ${ }^{38}$ In the end, the case was dismissed, mostly due to the lack of standing AIME had to bring the suite against UCLA, a state agency, in federal court. While the judge did not 
expressly rule on the fair-use argument UCLA made, the ruling did confirm that streaming is not a form of video distribution and that the public-performance argument UCLA made regarding the videos was not invalidated by the fact that they made copies of the videos in question. ${ }^{39}$

\section{Digitization Programs and the Google Book Settlement}

Librarians looking to digitize print collections, either for preservation or to facilitate online access, are also grappling with the copyright monopoly. Librarians who do not have the time or resources to seek permission from publishers and authors before scanning a book in their collection cannot touch anything published after 1922. LibraryLaw.com provides a helpful chart directed at librarians considering digitization projects, but the overwhelming fine print below the chart speaks to the labyrinthine nature of copyright. ${ }^{40}$

The Google Book settlement continues to loom large over both the library profession and the publishing industry. At the heart of debate is Google's Library Project, which is part of Google Book Search, originally named Google Print. ${ }^{41}$ The Library Project allows users to search for books using Google's algorithms to provide at its most basic a "snippet view" of the text from a relevant publication. Authors and publishers could also grant their permission to allow a view of select sample pages, and of course if the book is in the public domain, then Google can make the entire work visible online. ${ }^{42}$ In all cases, the user will see a "buy this book" link so that he or she could purchase the publication from online vendors on unrelated sites. ${ }^{43}$ Google hoped to sidestep the copyright permission quandary for a digitization project of this scale, announcing that it would proceed with the digitization of cooperative library collections and that it would be the responsibility of publishers and authors to actively opt out or vocalize their objection to seeing their works digitized and posted online. ${ }^{44}$ Google attempted to turn the copyright permissions process on its head, which was the basis of the class action lawsuit Authors Guild v. Google Inc. ${ }^{45}$ Before the settlement was reached, Google pointed to Kelly v. Arriba Soft Corp as proof that the indexing functions of an Internet search engine constitute fair use. In that 2002 case, the Ninth Circuit Court of Appeals found that a website's posting of thumbnail images, or "imprecise copies of low resolution, scaled down images," constitutes fair use, and Google argued its "snippet view" function is equivalent to a thumbnail image. ${ }^{46}$

However, Judge Denny Chin rejected the Google Book settlement in March 2011, citing the fact that Google would in essence be "exploiting books without the permission of copyright owners" and could also establish a monopoly over the digitized books market. The decision did in the end hinge on the fact that Google wanted to follow an opt-out program for copyright holders rather than an affirmative opt-in system. ${ }^{47}$

The Google Book settlement was dismissed without prejudice, leaving the door open to further negotiations between the parties concerned. Going forward, the library community should be concerned with how Google will handle orphan works and how its index of digitized works will be made available to libraries and the public. The 2008 settlement granted Google the nonexclusive right to digitize all books published before January 5, 2009, and in exchange, Google would have 
"paid 70\% of the net revenue earned from uses of Google Book Search in the United States to rights holders." 48 In addition, Google would have established the Book Rights Registry to negotiate with Google and others seeking to "digitize, index or display" those works on behalf of the rights holders. ${ }^{49}$ Approval of the settlement would have allowed Google to move forward with plans to expand Google Book Search and "to sell subscriptions to institutions and electronic versions of books to individuals." ${ }^{50}$ The concern that Judge Denny Chin expressed over a potential Google Book monopoly was widespread among the library community. While the settlement would not have given Google exclusive rights to digitize and display these copyrighted works, Google planned to ensure via the settlement that it would have received the same terms the Book Rights Registry negotiated with any third-party digital library, while also inoculating itself against the risk of any copyright infringement lawsuits that could be filed against a competitor. ${ }^{51}$ That would have left libraries vulnerable to any subscription price increases for the Google Books service. ${ }^{52}$

Libraries should carefully watch the negotiations around any future Google Books settlement, paying attention to a few key issues. ${ }^{3}$ There was considerable concern that under the terms of the 2008 settlement, even libraries participating in the Google Books Library Project would need to subscribe to the service to have access to digitized copies of the books in their own collections. ${ }^{53}$ Many librarians also vocalized their disappointment in Google's abandonment of its fair-use argument when it agreed to the 2008 settlement, which, if it succeeded, would have been a boon to nonprofit, library-driven digitization programs. ${ }^{54}$ Finally, many librarians were concerned that Google's Book Rights Registry was likely to become the default rights holder for the orphan works in the Google Books library, and that claims that Google Books is an altruistic effort to establish a world library conceals the less admirable aim of the project-to monetize out-of-print and orphan works. ${ }^{55}$

\section{Librarians as Free Culture Advocates: Implications and Recommendations}

Our digital nation has turned copyright law into a minefield for both librarians and the public at large. Intellectual property scholar Lawrence Lessig failed in his attempt to argue before the Supreme Court that the Sonny Bono Copyright Term Extension Act was an attempt to regulate free speech and therefore violated the First Amendment. ${ }^{56}$ But many believe that our restrictive copyright laws at least violate the intent of the progress clause of the Constitution, if not the First Amendment: "unconstrained access to past works helps determine the richness of future works. Inversely, when past works are inaccessible except to a privileged minority, future works are impoverished." ${ }^{77}$ While technological advances have placed the digital means of production into the hands of the masses, intellectual property law is leading us down a path to self-censorship. ${ }^{58}$ As the profession "at the heart of both the knowledge economy and a healthy democracy," 59 it is in our best interest as librarians to recognize the important role we have to play in restoring the balance to copyright law. To engage in the debate over copyright law in the digital age, the library community needs to educate itself and advocate for our own self-interests, focusing on three key areas: 
1. Copyright law in the classroom and at the conference. We must educate new and seasoned librarians on the nature of copyright law, and the impact it has on library practice and systems. Library schools must step up to the plate and include a thorough overview of copyright law in their library science curriculum. While including copyright law in a larger legal-issues class is acceptable, the complexity of current U.S. copyright law demonstrates that this is not a subject that can be glossed over in a single lecture. Furthermore, there needs to be a stronger emphasis on continuing education and training on copyright law within the library profession. The SLA offers a copyright certificate program, but the reach of such programs is not wide enough. Copyright law, and the impacts current policy has on the library profession, must be prominently featured at library conferences. The University of Maryland University College's Center for Intellectual Property offers an online community forum for discussing copyright issues and policies, but it is unclear how many librarians are members. ${ }^{60}$

2. Librarians as standard-bearers for the free culture movement. While the Library Copyright Alliance, to which the ALA, ARL, and ACRL all belong, files amicus briefs in support of balanced copyright law and submits comments to WIPO, the wider library community must also advocate for copyright reform, since this is an issue that affects all librarians, everywhere. As a profession, we need to throw our collective weight behind legislative measures that address the copyright monopoly. There have been a number of unfortunate failures in recent years. S. 1621, or the Consumers, Schools, and Libraries Digital Management Awareness Act of 2003, attempted to address a number of DRM issues, including a requirement that access controlled digital media and electronics include disclosures on the nature of the DRM technology in use. ${ }^{61}$ H.R. 107, the Digital Media Consumers Rights Act of 2003, would have amended the DMCA to allow those researching the technology to circumvent DRM software while also eliminating the Catch-22 that makes circumventing DRM software for fair-use purposes illegal. The BALANCE Act of 2003 (H.R. 1066) included provisions to expand fair use to the act of transmitting, accepting, and saving a copyrighted digital work for personal use. All of this legislation died in committee, as did H.R. 5889 (Orphan Works Act of 2008) and S. 2913 (Shawn Bentley Orphan Works Act of 2008). Both bills would have addressed the orphan works dilemma, clearly spelling out the steps one must take to use an orphan work with no express permission from the copyright holder, without fear of a future lawsuit. Could a show of support from the library community have saved these bills? It is impossible to know, but it is in our best interest to follow these legislative battles in the future and make sure our voice is heard.

3. Libraries and the Creative Commons phenomenon. In addition, librarians need to take part in the Creative Commons (CC) movement by actively directing patrons towards this world of digital works that have clear, simple use and attribution requirements. Creative Commons was founded in 2001 with the support of the Center for the Study of the Public Domain at Duke University School of Law. ${ }^{62}$ The movement is essentially about free culture, and the idea that many people want to share their creative works and allow others to use or build off of their efforts easily and without seeking their permission. It is not intended to supplant copyright law, and Lawrence 
Lessing, one of the founders of Creative Commons, has said many times that he believes intellectual property law is necessary and that piracy is inexcusable. ${ }^{63}$ Instead, a CC license states in clear terms exactly what rights the creator reserves, and conversely, what rights are granted to everyone else. ${ }^{64}$ As Lawrence Lessig explains,

You go to the Creative Commons Website (http://creativecomms.org); you pick the opportunity to select a license: do you want to permit commercial uses or not? Do you want to allow modifications or not? If you allow modifications, do you want to require a kind of copyleft idea that other people release the modifications under a similarly free license?

That is the core, and that produces a license. 65

There are currently six CC licenses, and they include some combination of the four license conditions defined by Creative Commons: attribution (by), share alike (sa), noncommercial (nc), and no derivatives (nd). ${ }^{66}$ Each of the four conditions is designated by a clever symbol, and the six licenses display these symbols after the Creative Commons trademark itself, two small $c$ 's inside a circle. ${ }^{67}$ There are "hundreds of millions of CC licensed works" that can be searched through Google and Yahoo, and some notable organizations that rely on CC licenses include Flickr, the Public Library of Science, Wikipedia, and now Whitehouse.gov. ${ }^{68}$ All librarians not already familiar with this approach need to educate themselves on CC licenses and how to find CC licensed works. ${ }^{69}$ While librarians must still inform their patrons about the realities of copyright law, it is just as important to direct patrons, students, and colleagues to CC licensed materials, so that they can create the mash-ups, videos, and podcasts that are the creative products of our Web 2.0 world. ${ }^{70}$ The Creative Commons system is not perfect, and "Creative Commons gives the unskilled an opportunity to fail at many junctures." 71 Yet that only speaks to the necessity of educating the library community about the "some rights reserved" movement, so that librarians, who are already called upon to understand traditional copyright law, are also educating our society about how individuals can protect their intellectual property while preserving and strengthening the public domain.

\section{CONCLUSION}

The library community can no longer afford to consider intellectual property law as a foreign topic appropriate for law schools but not library schools. Those who are behind the slow extermination of the public domain rely on the complexity of copyright law, and the misunderstanding of the principle of fair use, to make their arguments easier and to brow beat libraries and the public into handing over the rights the Constitution bestows on everyone. Librarians need to engage in the debate over copyright law to retain control over their collections, and to better serve their patrons. In the past, the library community has not hesitated to stand up for the freedom of speech and self-expression, whether it means taking a stand against banning books from school libraries or fighting to repeal clauses of the USA PATRIOT Act. Today's library patrons are not just information consumers - they are also information producers. Therefore it is just as critical for librarians to advocate for their creative rights as it is for them to defend their freedom to read. 
The Internet has become such a strong incubator of creative expression and innovation that the innovators are looking for a way to shirk the very laws that were designed to protect their interests. In the end, the desire to create and innovate seems to be more innate than those writing our intellectual property laws expected. Perhaps financial gain is less of a motivator than the pleasure of sharing a piece of ourselves and our worldview with the rest of society. Whether that's the case or not, what is clear is that if we do not roll back legislation like The Sonny Bono Copyright Term Extension Act and the DMCA so as to save the public domain, the pressure to create outside the bounds of the law is going to turn more inventors and artists into anarchists, threatening the interests of reasonable copyright holders. As librarians, we must curate and defend the creative property of the established, while fostering the innovative spirit of the next generation. As information, literature, and other creative works move out of the physical world, and off the shelves, into the digital realm, librarians need to do their part to ensure legislation is aligned with this new reality. If we do not, our profession may suffer first, but it will not be the last casualty of the copyright wars.

\section{REFERENCES}

1. Beverly Goldberg, "LG Unlocks Doors for Creators, Consumers with DMCA Exceptions," American Libraries 41, no. 9 (Summer 2010): 14.

2. Ibid.

3. Goldberg, "LG Unlocks Doors."

4. Christopher Alan Jennings, Fair Use on the Internet, prepared by the Congressional Research Service (Washington, DC: Library of Congress, 2002), 2.

5. Ibid., 1.

6. Ibid.

7. Brandon Butler, "Urban Copyright Legends," Research Library Issues 270 (June 2010): 18.

8. Robin Jeweler, "Digital Rights" and Fair Use in Copyright Law, prepared by the Congressional Research Service (Washington, DC: Library of Congress, 2003), 5.

9. Rachel Bridgewater, "Tipping the Scales: How Free Culture Helps Restore Balance in the Age of Copyright Maximalism," Oregon Library Association Quarterly 16, no. 3 (Fall 2010): 19.

10. Charles W. Bailey Jr., "Strong Copyright + DRM + Weak Net Neutrality = Digital Dystopia?" Information Technology \& Libraries 25, no. 3 (Summer 2006): 117; U.S. Copyright Office, "Copyright Law of the United States," under "Chapter 3: Duration of Copyright," http://www.copyright.gov/title17 (accessed December 8, 2010).

11. Dan Hunter, "Culture War," Texas Law Review 83, no. 4 (2005): 1130.

12. Bailey, "Strong Copyright," 118.

13. U.S. Copyright Office, "Copyright Law of the United States," under "Chapter 1: Subject Matter and Scope of Copyright," http://www.copyright.gov/title17 (accessed December 8, 2010).

14. Bailey, "Strong Copyright," 118.

15. Mary Minnow, "Library Digitization Table," http://www.librarylaw.com/DigitizationTable.htm (accessed December 8, 2010). 
16. Brian T. Yeh, "Orphan Works" in Copyright Law, prepared by the Congressional Research Service (Washington, DC: Library of Congress, 2002), summary.

17. Ibid.

18. JISC, In from the Cold: An Assessment of the Scope of "Orphan Works" and its Impact on the Delivery of Services to the Public (Cambridge, UK: JISC, 2009), 6.

19. Ibid.

20. Andrew Albanese, "HathiTrust Suspends its Orphan Works Release," Publishers Weekly, Sept, 16, 2011, http://www.publishersweekly.com/pw/bytopic/digital/copyright/article/48722-hathitrust-suspends-its-orphan-works-release-.html (accessed October 13, 2011).

21. U.S. Copyright Office, "Copyright Law of the United States," under "Chapter 1."

22. U.S. Copyright Office, Copyright Basics (Washington, DC: U.S. Copyright Office, 2000), www.copyright.gov/circs/circl/html (accessed December 8, 2010).

23. Mary Minnow, California Library Association, "Library Copyright Liability and Pirating Patrons," http://www.cla-net.org/resources/articles/minow pirating.php (accessed December 10, 2010).

24. Bailey, "Strong Copyright," 118.

25. Overdrive, "Copyright," http://www.overdrive.com/copyright.asp (accessed December 13, 2010).

26. Josh Hadro, “HarperCollins Puts 26 Loan Cap on EBook Circulations,” Library Journal (February 25 2011), http://www.libraryjournal.com/lj/home/889452-

264/harpercollins puts 26 loan cap.html.csp (accessed October 13, 2011).

27. Butler, "Urban Copyright Legends," 18.

28. Bailey, "Strong Copyright," 118.

29. Library of Congress, Fair Use on the Internet, 3.

30. Ibid., summary.

31. Matthew K. Dames, "Education Use in the Digital Age," Information Today 27, no. 4 (April 2010): 18.

32. Ibid.

33. Dames, "Education Use in the Digital Age,"18.

34. Matthew K. Dames, "Making a Case for Copyright Officers," Information Today 25, no. 7 (July 2010): 16.

35. William C. Dougherty, “The Copyright Quagmire," Journal of Academic Librarianship 36, no. 4 (July 2010): 351.

36. Ibid.

37. Library of Congress, "Digital Rights" and Fair Use in Copyright Law, 9.

38. Dougherty, "The Copyright Quagmire," 351.

39. Kevin Smith, "Streaming Video Case Dismissed," Scholarly Communications @ Duke, October 4, 2011, http://blogs.library.duke.edu/scholcomm/2011/10/04/streaming-video-casedismissed/ (accessed October 13, 2011). 
40. Dougherty, “The Copyright Quagmire," 351.

41. LibraryLaw.com, "Library Digitization Table."

42. Kate M. Manuel, The Google Library Project: Is Digitization for Purposes of Online Indexing Fair Use Under Copyright Law, prepared by the Congressional Research Service (Washington, DC: Library of Congress, 2009), 1-2.

43. Jeweler, "Digital Rights" and Fair Use in Copyright Law, 2.

44. Ibid.

45. Ibid.

46. Manuel, The Google Library Project, 2.

47. Amir Efrati and Jeffrey A. Trachtenberg, "Judge Rejects Google Books Settlement," Wall Street Journal, March 23, 2011, http://online.wsj.com/article/SB10001424052748704461304576216923562033348.html (accessed October 13, 2011).

48. Jennings, Fair Use on the Internet, 7.

49. Manuel, The Google Library Project, 2.

50. Ibid., 9-10.

51. Ibid.

52. Ibid.

53. Pamela Samuelson, "Google Books is Not a Library," Huffington Post, October 13, 2009, http://www.huffingtonpost.com/pamela-samuelson/google-books-is-not-a-lib b 317518.html (accessed December 10, 2009).

54. Ivy Anderson, "Hurtling Toward the Finish Line: Should the Google Book Settlement be Approved?" Against the Grain 22, no. 3 (June 2010): 18.

55. Samuelson, "Google Books is not a Library."

56. Jeweler, "'Digital Rights" and Fair Use in Copyright Law, 3.

57. Bailey, "Strong Copyright," 116.

58. Cushla Kapitzke, "Rethinking Copyrights for the Library through Creative Commons Licensing," Library Trends 58, no. 1 (Summer 2009): 106.

59. Ibid.

60. University of Maryland University College, "Member Community," Center for Intellectual Property, http://cipcommunity.org/s/1039/start.aspx (accessed February 21, 2011).

61. Robin Jeweler, Copyright Law: Digital Rights Management Legislation, prepared by the Congressional Research Service (Washington, DC: Library of Congress, 2004), summary.

62. Creative Commons, "History," http://creativecommons.org/about/history/ (accessed December 8, 2010).

63. Lawrence Lessig, "The Vision for the Creative Commons? What are We and Where are We Headed? Free Culture," in Open Content Licensing: Cultivating the Creative Commons, ed. Brian Fitzgerald (Sydney: Sydney University Press, 2007), 42.

64. Steven J. Melamut, "Free Creativity: Understanding the Creative Commons Licenses," American Association of Law Libraries 14, no. 6 (April 2010): 22. 
65. Lessig, "The Vision for the Creative Commons?" 45.

66. Creative Commons, "About," http://creativecommons.org/about/ (accessed December 8, 2010).

67. Ibid.

68. Ibid.

69. Bridgewater, "Tipping the Scales," 21.

70. Ibid.

71. Woody Evans, “Commons and Creativity," Searcher 17, no. 9 (October 2009): 34. 